\title{
Phosphorylation of Podocalyxin (Ser415) Prevents RhoA and Ezrin Activation and Disrupts Its Interaction with the Actin Cytoskeleton
}

\author{
Hirotaka Fukasawa, ${ }^{+\dagger}$ Hiroaki Obayashi, ${ }^{+\dagger}$ \\ Sandra Schmieder, ${ }^{\dagger \ddagger}$ Jaesung Lee, ${ }^{\dagger \S}$ \\ Pradipta Ghosh, " and Marilyn G. Farquhar ${ }^{\dagger}$ \\ From the Departments of Cellular and Molecular Medicine ${ }^{\dagger}$ and \\ Medicine, "Iniversity of California-San Diego, La Jolla, \\ California; the Department of Medicine," Hamamatsu University \\ School of Medicine, Japan; the Niigata University Graduate \\ School of Medical and Dental Sciences, ${ }^{+\dagger}$ University of Niigata, \\ Japan; IBSV, Institut Agrobiotech, ${ }^{\ddagger}$ Université de Nice-Sophia \\ Antipolis, France; and the Sanford-Burnham Medical Research \\ Institute, ${ }^{\S}$ La Jolla, California
}

Podocalyxin (PC) is a polysialylated, anti-adhesin that is essential for maintaining foot process architecture and the integrity of the glomerular filtration barrier. We showed previously that PC is firmly attached to the actin cytoskeleton through ezrin, that in puromycin aminonucleoside (PAN)-mediated nephrosis the PC-ezrin-actin complex is disrupted, and that $P C$ is uncoupled from actin. However, the precise mechanisms involved remained unknown. Here we show that detachment of PC from actin is regulated by phosphorylation of PC. PC is hyperphosphorylated at serines in PAN- and protamine sulfate (PS)-treated rat glomeruli. We determined that PC is a substrate of PKC and that the site of phosphorylation is Ser 415 , located within the juxtamembrane, ezrin-binding domain of the cytoplasmic tail of PC. Mutation of Ser415 to the phosphomimetic residues Glu (S415E) or Asp (S415D) interfered with direct binding of the PC cytoplasmic tail to ezrin in vitro. Moreover, stable expression of a phosphomimetic (S415E) PC mutant but not the WT or the phosphorylation-deficient (S415A) PC mutant, disrupted PC-ezrin-actin interaction, failed to activate RhoA, and the cytoskeletal linker, ezrin, remained inactive. Our data indicate that phosphorylation of $\mathrm{PC}$ at Ser415 prevents attachment of $P C$ and ezrin to actin and highlights the strategic position of Ser415 and direct binding of $\mathrm{PC}$ to ezrin in regulating podocyte foot process architecture. (Am J Pathol 2011, 179:2254-2265; DOI: 10.1016/j.ajpath.2011.07.046)

The unique foot process and filtration slit architecture of glomerular podocytes is essential for maintaining glomerular filtration. Disruption of this organization is characteristically seen in glomerular diseases associated with proteinuria. Although the molecular mechanisms that lead to these derangements are not fully understood, it has become clear that the apical (eg, podocalyxin) and basal (integrins, dystroglyans) membrane proteins of the podocyte as well as slit diaphragm proteins (nephrin) are normally anchored to the dense actin network in the foot processes $^{1}$ and that this network undergoes substantial changes in the nephrotic syndrome..$^{2-6}$

We have previously shown that podocalyxin (PC), the major apical sialoglycoprotein of the podocyte, serves as an anti-adhesin that maintains the filtration slits between the foot processes open by its high negative charge. ${ }^{7}$ In addition, we have demonstrated that the intracellular domain of PC is anchored to the actin cytoskeleton through ezrin, ${ }^{8}$ a member of the ERM (ezrin-radixin-moesin) family of actin-binding proteins. PC is unusual as it binds ezrin both directly ${ }^{9}$ and indirectly ${ }^{10}$ through NHERF2 $\left(\mathrm{Na}^{+} / \mathrm{H}^{+}\right.$-exchanger regulatory factor 2$)$, a PDZ protein, and participates in maintaining foot process architecture via activation of the small GTPase Rho. RhoA, a positive regulator of actin filament bundling, can phosphorylate and activate ezrin, ${ }^{11}$ and activated ezrin links PC and various other plasma membrane proteins to the actin cytoskeleton. ${ }^{12,13}$ Activated ezrin also binds and sequesters RhoGDI, ${ }^{14-17}$ thereby initiating activation of RhoA and maintaining ezrin activation. ${ }^{18}$ Thus, RhoA and ezrin form a positive feedback loop that functions in regulation

Supported by NIH grant R27 DK17724 (M.G.F). P.G. was supported by Burroughs Wellcome Fund (1008353 GHOSH 8/15).

Accepted for publication July 12, 2011.

H.F. and H.O. contributed equally to this work.

Address reprint requests to Marilyn Gist Farquhar, Ph.D., Department of Cellular and Molecular Medicine, 9500 Gilman Dr., University of CaliforniaSan Diego, La Jolla, CA 92093-0651. E-mail: mfarquhar@ucsd.edu. 
of cell shape. The precise mechanism by which PC activates RhoA and maintains foot process architecture in normal podocytes and the basis for disruption of this architecture in glomerular diseases associated with proteinuria and foot process effacement remain to be clarified. In this paper we show that phosphorylation of PC is enhanced in glomeruli of puromycin aminonucleoside (PAN)- and protamine sulfate (PS)-treated rats, rat models in which there is a loss of foot processes and dramatic reorganization of the actin cytoskeleton. ${ }^{5,6}$ We further pinpoint Ser415 as the crucial phosphorylation site that regulates the interaction between $\mathrm{PC}$ and ezrin, thereby linking PC to the actin cytoskeleton. We also provide evidence that in nephrotic podocytes phosphorylation of $\mathrm{PC}$ in the ezrin binding domain leads to inactivation of the RhoA-ezrin signaling cascade, a pathway previously implicated in derangement of foot process architecture. ${ }^{9,10}$

\section{Materials and Methods}

\section{Materials}

Chemical reagents were from Sigma (St. Louis, MO) or Fisher Biotech (Tustin, CA) and detergents were from Sigma or Calbiochem (San Diego, CA). Kodak Biomax MR film was obtained from Fisher Biotech.

\section{Antibodies}

Mouse anti-PC monoclonal antibodies (mAb) $5 \mathrm{~A}$ and $1 \mathrm{~A}$ and rabbit anti-PC polyclonal (0601) were raised as described previously. ${ }^{7}$ Rabbit anti-ezrin (3C12) (NeoMarkers, Fremont, CA), anti-phosphorylated ezrin mAb, which specifically recognizes phosphorylated Thr567 of ezrin (Cell Signaling Technology, Danvers, MA), anti-phosphoserine IgG (Invitrogen, Carlsbad, CA), anti-phosphothreonine IgG (Cell Signaling Technology), and mouse anti-phosphotyrosine IgG (BD Biosciences, San Jose, $\mathrm{CA}$ ), anti- $\beta$-actin mAb (AC-15) (Sigma, St. Louis, MO), and mouse anti-RhoA mAb (26C4) (Santa Cruz Biotechnology, Santa Cruz, CA) were obtained commercially. Rabbit anti-EBP50 (NHERF1) was provided by Dr. Anthony Bretscher (Cornell University, Ithaca, NY). Horseradish peroxidase-conjugated goat anti-rabbit and antimouse IgGs were purchased from Promega (Madison, WI). Alexa 488 conjugated goat anti-mouse IgG used for immunofluorescence was from Molecular Probes (Eugene, OR). Goat anti-rabbit or anti-mouse Alexa Fluor 680 or IRDye $800\left(\mathrm{FCab}^{\prime}\right)_{2}$ for immunoblotting were from LICOR Biosciences (Lincoln, NE).

\section{Preparation of Rat Glomeruli}

Glomerular fractions (containing $>95 \%$ glomeruli) were isolated from kidney cortices of male Sprague-Dawley rats (Charles River Laboratories, Boston, MA) by graded sieving as described previously. ${ }^{8}$ All animal experiments were done in accord with $\mathrm{NIH}$ Guidelines for the Care and Use of Laboratory Animals.

\section{Induction of Puromycin Aminonucleoside-Mediated Nephrosis}

Male rats $(\sim 150 \mathrm{~g})$ were injected once intraperitoneally with puromycin aminonucleoside (PAN; $15 \mathrm{mg} / 100 \mathrm{~g}$ body weight) as described previously ${ }^{10}$ and sacrificed on the third or 10th day after injection.

\section{Perfusion with Protamine Sulfate}

Male rats (200 to $250 \mathrm{~g}$ ) were anesthetized with Metrofane (methoxyflurane), and both kidneys were perfused in situ through the abdominal aorta at a pressure of $\sim 100$ $\mathrm{mm} \mathrm{Hg}$ and an infusion rate of 6 to $12 \mathrm{~mL} / \mathrm{min}$ as described previously with slight modifications. ${ }^{19,20}$ Initially, the kidneys were flushed with HBSS (Hanks balanced salt solution) at $37^{\circ} \mathrm{C}$ for 2 minutes, after which protamine sulfate (PS; $500 \mu \mathrm{g} / \mathrm{mL}$ in HBSS) was perfused at $37^{\circ} \mathrm{C}$ for 15 minutes. The kidneys remained immersed in a water bath at $37^{\circ} \mathrm{C}$ during the entire perfusion period.

\section{Preparation of Glomerular Lysates}

Glomerular lysates were prepared by incubation of isolated glomeruli in 1\% Triton X-100, 0.5\% Nonidet P-40, 150 $\mathrm{mmol} / \mathrm{L} \mathrm{NaCl}, 10 \mathrm{mmol} / \mathrm{L}$ Tris- $\mathrm{HCl}, \mathrm{pH}$ 7.6, $1 \mathrm{mmol} / \mathrm{L}$ ethylenediamine-tetraacetic acid (EDTA), $1 \mathrm{mmol} / \mathrm{L}$ ethylene glycol-bis(oxyethylenenitrilo)tetraacetic acid (EGTA) ${ }^{21}$ supplemented with $1 \times$ Complete, EDTA-free protease inhibitor cocktail (Roche, Mannheim, Germany) and phosphatase inhibitors $(50 \mathrm{mmol} / \mathrm{L}$ sodium fluoride and 1 $\mathrm{mmol} / \mathrm{L}$ sodium vanadate) at $4^{\circ} \mathrm{C}$ for 60 minutes, and detergent insoluble material was removed by centrifugation $(10,000 \times g$ for 10 minutes $)$.

\section{Sodium Dodecyl Sulfate-Polyacrylamide Gel Electrophoresis and Immunoblotting}

Protein concentration was measured by Quick Start Bradford Dye Reagent (Bio-Rad Laboratories, Hercules, CA). Proteins were separated by sodium dodecyl sulfate-polyacrylamide gel electrophoresis (SDS-PAGE) under reducing conditions and transferred to PVDF membranes (Millipore Corp., Bedford, MA) using a wet tank transfer system (Minigel-Transfer-Unit; Bio-Rad Laboratories) as described previously. ${ }^{10}$ Protein bands were detected by using enhanced chemiluminescence (Supersignal; Pierce Biotechnology, Rockford, IL) or the Odyssey imaging system (LI-COR Inc., Lincoln, NE), and the band intensities were quantified using ImageJ analysis software (http://rsbweb.nih.gov/ij).

\section{Alkaline Phosphatase Treatment}

Glomerular lysates $(10 \mu \mathrm{g})$ were suspended in dephosphorylation buffer [50 mmol/L Tris ( $\mathrm{pH} \mathrm{9.0),} 1 \mathrm{mmol} / \mathrm{L}$ $\mathrm{MgCl}_{2}, 0.1 \mathrm{mmol} / \mathrm{L} \mathrm{ZnCl}_{2}$, and $1 \mathrm{mmol} / \mathrm{L}$ spermidine], mixed with $18 \mathrm{U}$ alkaline phosphatase (Roche), incubated at $30^{\circ} \mathrm{C}$ for 2 hours, and immunoblotted for PC. 


\section{Immunoprecipitation}

Glomerular lysates were incubated with anti-PC (5A and $1 \mathrm{~A} \lg \mathrm{I}, 2 \mu \mathrm{g}$ each, or anti-pSer $\lg \mathrm{g}$ ) for 4 to 16 hours at $4^{\circ} \mathrm{C}$. Immune complexes were bound to protein $\mathrm{G}$ plus/ protein $\mathrm{A}$-agarose beads at $4^{\circ} \mathrm{C}$ for 1 hour, washed three times with lysis buffer, and boiled in $\times 2$ sample buffer for immunoblotting.

\section{Cell Culture and Transfection}

MDCK cells were maintained as described previously. 7,9 MDCK cells stably expressing PC or mutant PCs (S415E, S415A) in (p)IRES1neo ${ }^{7}$ or empty vector ${ }^{7}$ were generated using an electroporation system (Bio-Rad Laboratories, Inc., Hercules, CA) and selected in the presence of G418 antibiotics.

\section{In Vivo [ $\left.{ }^{32} P\right]$ Incorporation}

Confluent MDCK-PC cells were incubated in phosphatefree Dulbecco's modified Eagle's medium (DMEM) with $10 \%$ dialyzed phosphate-free fetal bovine serum (FBS) and $0.5 \mathrm{mCi}\left[{ }^{32} \mathrm{P}\right]$ orthophosphate for 4 hours. Cells were lysed and immunoprecipitated with anti-PC (PC; 5 A) or preimmune $\operatorname{lgG}(\mathrm{IgG})$. The immunoprecipitates were analyzed by SDS-PAGE followed by autoradiography or immunoblotting (IB) with anti-PC antibodies (5A and 0601).

\section{In Vitro Phosphorylation of the Podocalyxin Cytoplasmic Tail}

GST fusion proteins $(2.5 \mu \mathrm{g})$ of the cytoplasmic tail of PC [aa 411- 485; podocalyxin cytoplasmic tail (PCT)], juxtamembrane $\mathrm{N}$ terminal truncation mutant (aa 423-485; PCT $\Delta$ N12), or single point mutants (Ser415 to glutamic acid [S415E] or alanine [S415A]), were incubated with or without rat brain protein kinase $\mathrm{C}$ (PKC) (Calbiochem, San Diego, CA) in the presence of $\gamma$-[ ${ }^{32}$ P]ATP. A QuickChange site-directed mutagenesis kit (Stratagene, La Jolla, CA) was used to introduce point mutations in the PCT. The incubation mixture was analyzed by SDS-PAGE followed by autoradiography. To prepare phosphorylated PCT for use in GST pull-down assays, in vitro kinase assays were performed using bacterially expressed $\mathrm{His}$ $(6 \times$ His, hexahistidine) tagged PCT (His-PCT, aa 411485) proteins ( $\sim 15 \mu \mathrm{g}$ per reaction), and purified PKC or recombinant PKA kinases (1 ng/ $\mu \mathrm{L}$, final). Reactions were started by addition of $500 \mu \mathrm{mol} / \mathrm{L}$ ATP and performed at $25^{\circ} \mathrm{C}$ for 60 minutes in $50 \mu \mathrm{L}$ of kinase buffer $(80 \mathrm{mmo} / \mathrm{L}$ MES, pH 7.0, $5 \mathrm{mmol} / \mathrm{L} \beta$-glycerol phosphate, $2 \mathrm{mmol} / \mathrm{L}$ EGTA, $20 \mathrm{mmol} / \mathrm{L} \mathrm{MgCl}_{2}, 0.2 \mathrm{mmol} / \mathrm{L}$ sodium orthovanadate, $0.2 \mathrm{mmol} / \mathrm{L}$ DTT, and protease inhibitor cocktail for rat brain PKC; and $5 \mathrm{mmol} / \mathrm{L} \mathrm{Tris/HCl,} \mathrm{pH} 7.5$, $15 \mathrm{mmol} / \mathrm{L} \mathrm{MgCl}_{2}, 5 \mathrm{mmol} / \mathrm{L} \beta$-glycerol phosphate, 2 $\mathrm{mmol} / \mathrm{L}$ EGTA, $0.2 \mathrm{mmol} / \mathrm{L}$ sodium orthovanadate, and $0.2 \mathrm{mmol} / \mathrm{L}$ DTT for recombinant PKA). Sham-treated samples were treated identically at all steps except the kinase was omitted. Reactions were stopped by rapidly cooling to $4^{\circ} \mathrm{C}$, cleared of any aggregates by centrifugation at $14,000 \mathrm{~g}$, and used as source of PCT in pull-down assays (see below). Serine phosphorylation was confirmed on a small aliquot of the proteins by immunoblotting using anti-phosphoserine mAb (BD Biosciences).

\section{In Vitro Binding Assays}

For binding assays using recombinant proteins, cDNA encoding the cytoplasmic tail of PC (PCT) and juxtamembrane $\mathrm{N}$ terminal truncation mutant (PCT $\triangle \mathrm{N} 12$ ), and three single-point mutants (S415E, S415D, and S415A) were created as described above. 6-His-tagged proteins were produced according to the manufacturer's instructions. N-terminal ezrin (amino acids 1-310) was also amplified by PCR and inserted into pGEX-KG (Amersham Pharmacia Biotech, Piscataway, NJ), and GST fusion proteins were produced as described previously. ${ }^{9} 6$-Histagged PCT, PCT $\Delta \mathrm{N} 12, \mathrm{~S} 415 \mathrm{E}$, and S415A were incubated for 2 hours at $4^{\circ} \mathrm{C}$ with equal aliquots $(2.5 \mu \mathrm{g})$ of GST alone or GST-ezrin immobilized on glutathione-Sepharose beads in $500 \mathrm{mmol} / \mathrm{L} \mathrm{NaCl}, 20 \mathrm{mmol} / \mathrm{L}$ Tris- $\mathrm{HCl}$, $\mathrm{pH} 8.0$, and $0.2 \%$ Triton $\mathrm{X}-100$ containing $1 \mathrm{x}$ Complete. Beads were subsequently washed four times with $1 \mathrm{~mL}$ PBST wash buffer $(0.1 \%$ Tween $20,5 \mathrm{mmol} / \mathrm{L}$ ethylenediaminetetraacetic acid (EDTA), $10 \mathrm{mmol} / \mathrm{L} \mathrm{MgCl}_{2}$ ). Bound proteins were eluted by boiling in Laemmli's sample buffer and analyzed by immunoblotting with polyclonal anti-PC (0601). For binding assays using in vitro phosphorylated 6-His-PCT and GST-N'-Ezrin, binding was performed for 4 hours at $4^{\circ} \mathrm{C}$ with equal aliquots (15 $\mu \mathrm{g}$ ) of GST alone or GST-ezrin immobilized on glutathioneSepharose beads. Binding and wash buffers were supplemented with $10 \mathrm{mmol} / \mathrm{L} \mathrm{Na}$ pyrophosphate and 0.1 $\mathrm{mmol} / \mathrm{L} \mathrm{Na}$ orthovanadate.

For binding assays using glomerular lysates, $60 \mu \mathrm{g}$ of rat glomerular cell lysate from normal rats or 10 day PAN rats were incubated overnight at $4^{\circ} \mathrm{C}$ with equal aliquots $(10 \mu \mathrm{g})$ of recombinant GST or GST-N'-Ezrin immobilized on glutathione-Sepharose beads in $950 \mathrm{mmol} / \mathrm{L} \mathrm{Tris-HCl}$, $\mathrm{pH}$ 7.4, $100 \mathrm{mmol} / \mathrm{L} \mathrm{NaCl}, 0.4 \%$ (v:v) NP-40, $10 \mathrm{mmol} / \mathrm{L}$ $\mathrm{MgCl} 2,5 \mathrm{mmol} / \mathrm{L}$ EDTA, $2 \mathrm{mmol} / \mathrm{L}$ DTT, protease inhibitor cocktail). Beads were washed $(\times 3)$ with $1 \mathrm{~mL}$ wash buffer, eluted by boiling in sample buffer, separated by SDS-PAGE and analyzed by immunoblotting with polyclonal anti-PC (0601).

For binding assays using in vitro-translated proteins, cDNA encoding PCT, PCT $\triangle N 12$, S415D, S415E, and S415A were amplified by PCR and inserted into pGEX$K G$, and GST fusion proteins were produced as described previously. ${ }^{9}{ }^{35} \mathrm{~S}$-labeled, $\mathrm{N}$-terminal ezrin was produced using the TNT T7 Quick Coupled Transcription/ Translation system (Promega, Madison, WI) in the presence of $\left[{ }^{35}\right.$ S]methionine and pCR3 constructs (provided by Dr. Heinz Furthhmayr, Stanford University, Stanford, CA). In vitro-translated ezrin was incubated for 2 hours at $4^{\circ} \mathrm{C}$ with equal aliquots $(2.5 \mu \mathrm{g})$ of GST or GST fusion proteins of PC immobilized on glutathione-Sepharose beads in 200 $\mathrm{mmol} / \mathrm{L} \mathrm{NaCl}, 20 \mathrm{mmol} / \mathrm{L}$ Tris-HCl, $\mathrm{pH}$ 8.0, and 0.2\% Triton $\mathrm{X}-100$ containing $1 \times$ Complete. Beads were subsequently washed four times with $1 \mathrm{~mL}$ wash buffer. Bound proteins were eluted by boiling in sample buffer, separated by SDSPAGE, and analyzed by autoradiography. 


\section{Immunofluorescence Microscopy}

MDCK cells were grown on Costar Transwell filters (Corning, Palo Alto, CA) for 3 days, and after confluence were fixed in $2 \%$ paraformaldehyde, permeabilized, and incubated sequentially with the primary antibody followed by cross-absorbed Alexa 488 goat anti-mouse IgG (Molecular Probes, Eugene, OR). Actin was detected with Alexa 594-phalloidin. Cells were examined with a Zeiss LSM510 confocal microscope (UCSD Light Microscopy Core). Vertical $(X-Z)$ sections were generated in 0.3- $\mu \mathrm{m}$ steps. Confocal images were processed with Adobe Photoshop CS3.

\section{Differential Detergent Extraction}

Differential detergent extraction of cells was performed as described previously. ${ }^{7}$ Briefly, cells were lysed in Triton X-100 lysis buffer (0.5\% Triton X-100, $20 \mathrm{mmol} / \mathrm{L}$ HEPES, pH 7.4, $150 \mathrm{mmol} / \mathrm{L} \mathrm{NaCl}$, and $1 \mathrm{mmol} / \mathrm{L}$ EDTA), and centrifuged at $15,000 \mathrm{~g}$ for 30 minutes. The insoluble pellet was resuspended in the same volume of RIPA buffer $(0.1 \%$ SDS, $0.5 \%$ sodium deoxycholate, $1 \%$ Triton $\mathrm{X}-100,20 \mathrm{mmol} / \mathrm{L}$ HEPES, $\mathrm{pH}$ 7.4, $150 \mathrm{mmol} / \mathrm{L} \mathrm{NaCl}$, and
$1 \mathrm{mmol} / \mathrm{L}$ EDTA), and centrifuged as above. The resultant pellet was directly solubilized with the same volume of $1 \mathrm{x}$ sample buffer as the supernatant. Equal volumes of Triton X-100 soluble, RIPA soluble, and RIPA insoluble pellet were analyzed by immunoblotting.

\section{Assay for Active RhoA}

A pull-down assay for active RhoA was performed with a GST fusion protein containing the Rho-binding domain (GST-RBD) of Rhotekin (provided by Dr. Martin Schwarz, University of Virginia, Charlottesville, VA). ${ }^{22}$ MDCK cells were lysed in $1 \%$ Triton $X-100,0.5 \%$ sodium deoxycholate, $0.1 \%$ SDS, $50 \mathrm{mmol} / \mathrm{L}$ Tris- $\mathrm{HCl}, \mathrm{pH}$ 7.2, $500 \mathrm{mmol} / \mathrm{L} \mathrm{NaCl}$, and $10 \mathrm{mmol} / \mathrm{L} \mathrm{MgCl}_{2}$ containing $1 \times$ Complete. After centrifugation, lysates were incubated 90 minutes at $4^{\circ} \mathrm{C}$ with $10 \mu \mathrm{g}$ GST-RBD or GST alone immobilized on glutathione-Sepharose beads (Amersham Biosciences). Bound proteins were eluted in $1 x$ sample buffer, and active RhoA was detected by immunoblotting.
A

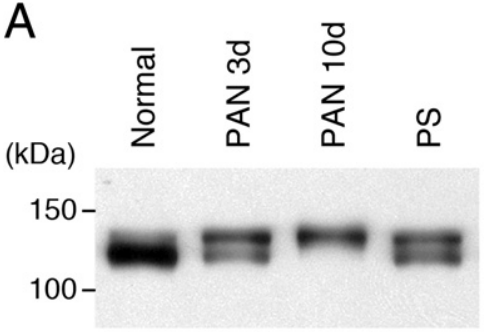

C
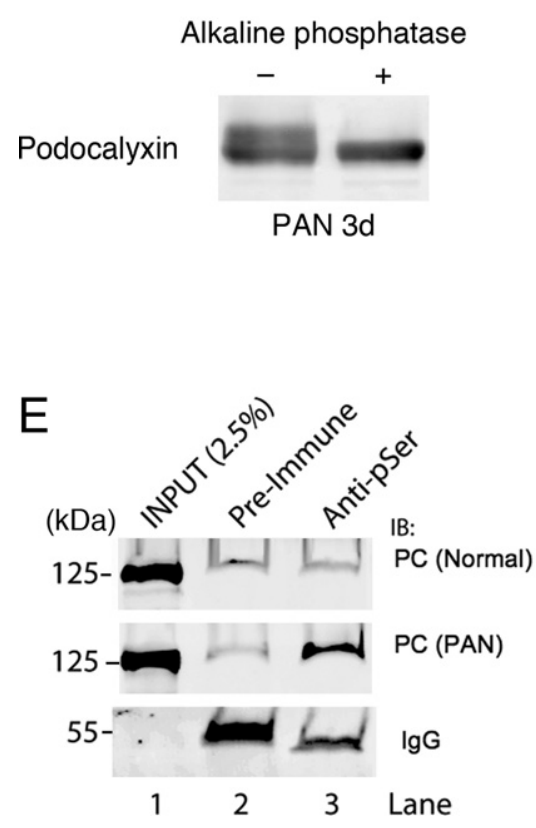

B

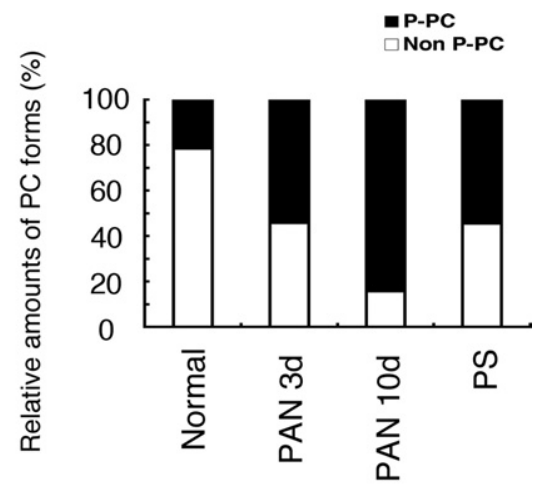

D

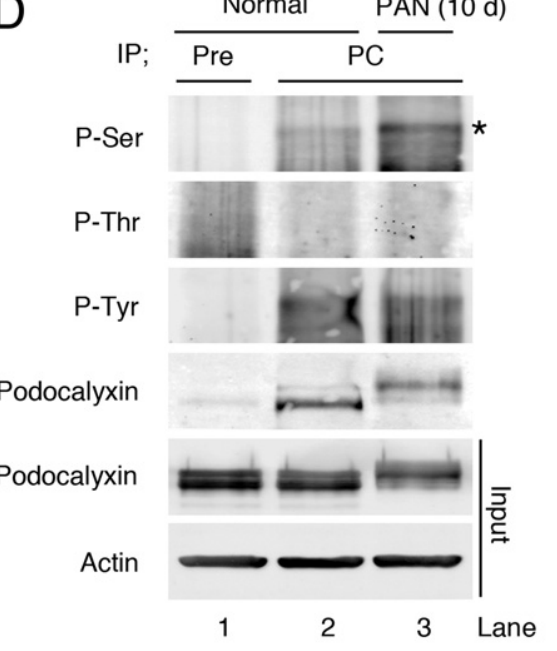

Figure 1. $\mathrm{PC}$ is serine-phosphorylated in nephrotic glomeruli. A: Immunoblot of glomerular lysates obtained from normal, PAN treated (3 to 10 days) and protamine sulfate (PS)-treated rats. PC is detected as two bands, $(\sim 120$ and $\sim 140 \mathrm{kDa}$ ). The lower band predominates in normal glomeruli whereas the upper band is stronger in PAN glomeruli, and the two bands are virtually equal in PS glomeruli. B: Densitometric analysis of the immunoblot shown in $\mathbf{A}$ showing that the percentage of $140 \mathrm{kDa}$ (phosphorylated) PC is increased in glomerular lysates from PAN- and PS-treated rats: In 3 days PAN and PS-treated rats phosphorylated PC is $45 \%$ of the total and in 10 days PAN nephrotic $90 \%$ of the total PC, whereas only $\sim 20 \%$ is phosphorylated in normal rats. C: The higher molecular weight form of PC disappears after alkaline phosphatase treatment of glomerular lysates from PAN-nephrotic rats, and the lower molecular weight form is correspondingly increased. Glomerular lysates $(10 \mu \mathrm{g})$ were incubated with $(+)$ and without $(-)$ alkaline phosphatase for 2 hours at $30^{\circ} \mathrm{C}$, separated by $8 \%$ SDS-PAGE, and immunoblotted with anti-PC (5A) IgG. D: Phosphoserine (star; pSer), but not phosphothreonine (pThr) or phosphotyrosine (pTyr) is increased in PC from PAN (lane 3) versus normal (lane 2) glomeruli. Glomerular lysates from normal or PAN-nephrotic rats (10 days) were incubated with preimmune (Pre) or anti-PC (PC) IgG for 16 hours at $4^{\circ} \mathrm{C}$. Immunoprecipitates bound to protein $G$ plus/protein A-agarose beads were immunoblotted with anti-pSer, -pThr, or -pTyrspecific IgGs. E: Phosphoserine is increased in PC from PAN (middle panel) versus normal (top panel) glomeruli. Glomerular lysates from normal or PAN-nephrotic rats (10 days) were incubated with preimmune IgG (lane 2) or antipSer IgG (lane 3) as in $\mathbf{D}$ and immunoblotted with anti-PC (0601) IgG. 


\section{Results}

\section{Phosphorylation of PC Is Increased in Nephrosis}

When glomerular lysates obtained from normal, PANtreated (3 and 10 days), and PS-treated rats, were analyzed by immunoblotting, PC was detected as two major bands, $\sim 120$ and $\sim 140 \mathrm{kDa}$ (Figure $1 \mathrm{~A}$ and B); however, their ratio varied in that the upper band was increased in PAN- and PS-treated rats, suggesting that PC is posttranslationally modified under these pathological conditions. Digestion of the lysates with alkaline phosphatase resulted in a shift in the electrophoretic mobility of PC from 140 to $120 \mathrm{kDa}$ (Figure 1C), indicating that the upper band represents a phosphorylated form of PC. Quantification revealed that in normal glomeruli, only $\sim 20 \%$ of PC is phosphorylated whereas in glomeruli from PS- and 3 days PAN-treated rats $\sim 45 \%$ was phosphorylated, and in glomeruli from 10 days PAN nephrotic rats most (>90\%) of the PC was phosphorylated (Figure 1B). Thus phosphorylation of $\mathrm{PC}$ is dramatically increased in glomerular lysates from PAN- and PS-treated rats. To determine the nature of the phosphorylation we performed immunoprecipitation on glomerular lysates with anti-PC IgG followed by immunoblotting with phospho-specific antibodies. We found that phosphoserine, but not phosphothreonine or phosphotyrosine, was increased in PC from nephrotic glomeruli (Figure 1D). We confirmed this finding using a complementary approach in which serine phosphoproteins were immunoprecipitated with anti-pSer IgG and probed for PC: PC was detected exclusively after PAN injury, indicating that $\mathrm{PC}$ is a prominent serine phosphoprotein in PAN-injured glomeruli (Figure 1E). Taken together, these results demonstrate that PC is heavily serine phos- phorylated under pathological conditions associated with foot process effacement.

\section{PC Is Phosphorylated in MDCK-PC Cells}

To confirm that PC can be phosphorylated in vivo, we performed [ $\left.{ }^{32} \mathrm{P}\right]$-labeling of MDCK-PC cells stably expressing $\mathrm{PC}{ }^{7}$ MDCK-PC cells were incubated with $\left[{ }^{32} \mathrm{P}\right]$ orthophosphate for 4 hours, and immunoprecipitation was performed with anti-PC IgG followed by autoradiography. As shown in Figure $2 \mathrm{~A},\left[{ }^{32} \mathrm{P}\right]$ was incorporated into $\mathrm{PC}$, indicating that $\mathrm{PC}$ is also phosphorylated in MDCK-PC cells.

\section{PKC Phosphorylates Ser415 Located within the Ezrin-Binding Domain of PC}

To gain insight into the specific phosphorylation site on the PC tail we used NetPhos 2.0 and NetPhosK 1.0 programs. Three potential candidates (Ser415, Tyr434, and Thr445) were predicted in the PC cytoplasmic tail. The highest scores were 0.984 at Tyr434 and 0.955 at Ser415 located at the juxtamembrane region of PC. We attempted to identify the phosphosite of PC isolated from nephrotic glomerular lysates by mass spectrometry; however, we were unsuccessful in generating suitable peptide fragments, so we decided instead to use site-directed mutagenesis. We focused on Ser415 because we found phosphoserine to be increased in PAN nephrosis, and the sequence flanking Ser415 contains a consensus sequence for PKC. Moreover, Ser415 is a part of the specific motif, HQRIS (aa 411-415), which we previously showed to represent the site in the PC tail that binds directly to ezrin. ${ }^{9}$ To determine whether

A

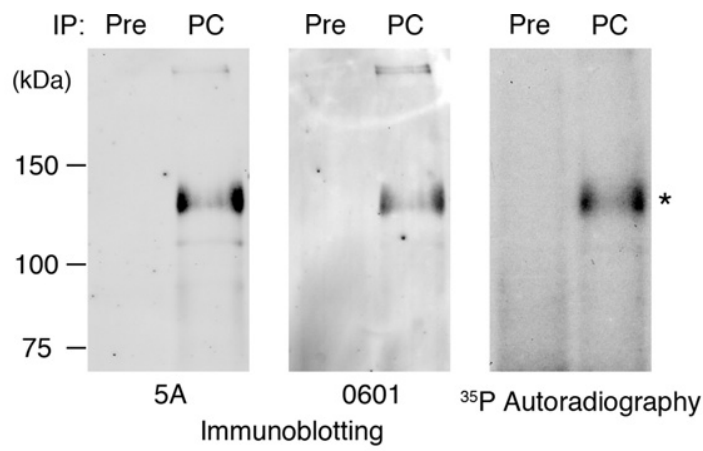

B

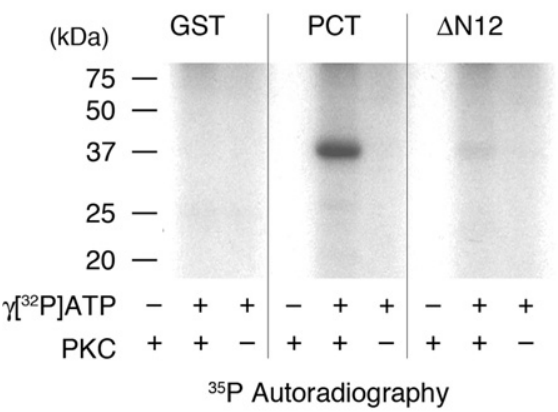

C

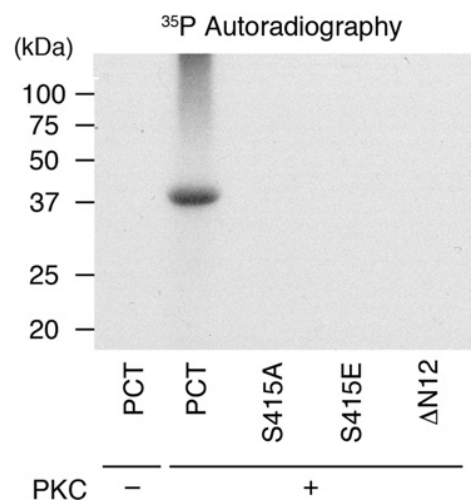

Figure 2. $\mathrm{PC}$ is phosphorylated in vivo and in vitro. A: Podocalyxin is phosphorylated in vivo. Confluent MDCK-PC cells stably expressing PC, were incubated in phosphate-free medium containing $10 \%$ phosphate-free FBS and $0.5 \mathrm{mC}$ $\left[{ }^{32} \mathrm{P}\right]$ orthophosphate for 4 hours. Cells were lysed, immunoprecipitated with anti-PC IgG (5A), and the immunoprecipitates were analyzed by autoradiography or by immunoblotting with anti-PC antibodies (mAb 5A, or polyclonal 0601). B: GST-PCT (PCT), but not PCT $\Delta$ N12 or GST alone are phosphorylated in the presence of both PKC and $\gamma$-[ $\left.{ }^{32} \mathrm{P}\right]$ ATP. GST-PCT (aa $411-$ 485 , corresponding to the entire cytoplasmic domain of podocalyxin), PCT $\Delta \mathrm{N} 12$, a truncation mutant lacking the 12 amino acid juxtamembrane domain of PC ( $\Delta 411-422)$, and GST alone were incubated with $(+)$ or without $(-)$ PKC and $\gamma-\left[{ }^{32} \mathrm{P}\right] \mathrm{ATP}$, and processed for autoradiography. C: Serine 415 of PC is phosphorylated by PKC. The same assay as in $\mathbf{B}$ was performed with GST-PCT, GST PCT $\Delta$ N12, and single point mutants at S415E or S415A of PCT in the presence of both PKC and $\gamma-\left[{ }^{32} \mathrm{P}\right] \mathrm{ATP}$. Full length PCT, but not PCT $\Delta \mathrm{N} 12$, S415E or S415A, was phosphorylated by PKC. 
Ser415 in the PC tail can be phosphorylated by PKC, we performed an in vitro phosphorylation assay: GST fusion proteins corresponding to the entire cytoplasmic tail of PC (PCT, aa 411-485), PCT $\Delta$ N12 (a juxtamembrane N-terminal $\Delta 411-422)$, truncation mutant, and GST alone were incubated with or without PKC and $\gamma-\left[{ }^{32} \mathrm{P}\right] \mathrm{ATP}$. We found that GST-PCT was phosphorylated in the presence of PKC and $\gamma$-[ $\left.{ }^{32} \mathrm{P}\right] \mathrm{ATP}$, whereas PCT $\Delta \mathrm{N} 12$ and GST alone were not (Figure 2B). Next we generated single-point mutants (Ser415 to Glu (S415E) and Ala (S415A)) and performed the same assay. GST-PCT was clearly phosphorylated by PKC, whereas PCT $\Delta$ N12, PC S415E, and PC S415A were not (Figure 2C). Taken together, these results indicate that
Ser415 is the only phosphorylation site for PKC within the PC tail.

\section{Phosphorylation of PC at Ser415 Prevents Direct Interaction with Ezrin}

Because Ser415 is located within the motif that directly binds ezrin, we next investigated whether PKC-mediated phosphorylation of PC at Ser415 affects the interaction between PC and ezrin. To test this possibility, we performed binding assays with GST-tagged, N-terminal Ezrin (GST-N'-Ezrin) immobilized on glutathione S- sep-
A

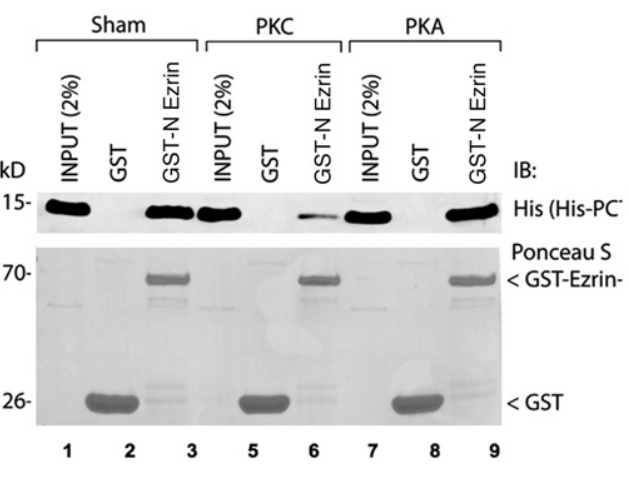

C 6-His-podocalyxin / GST-Ezrin

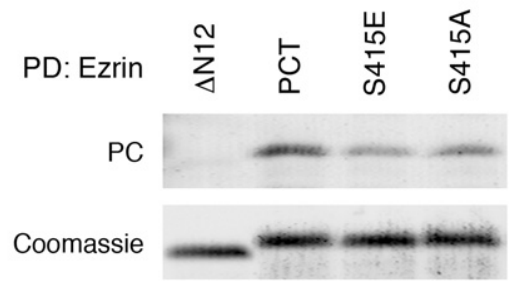

E GST-podocalyxin / TNT ${ }^{35 S}$-Ezrin

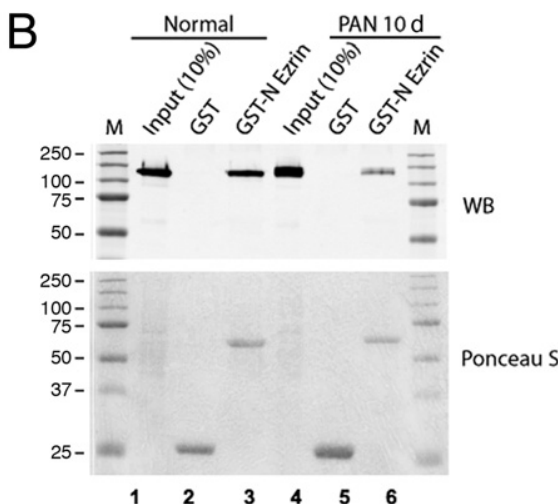

$\mathrm{D}$

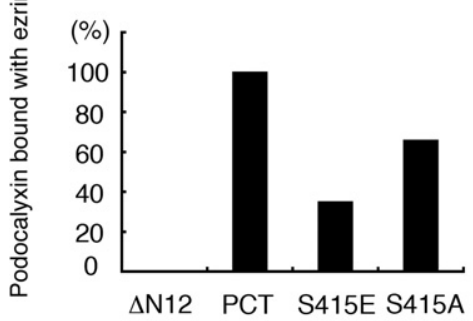

$\mathrm{F}$

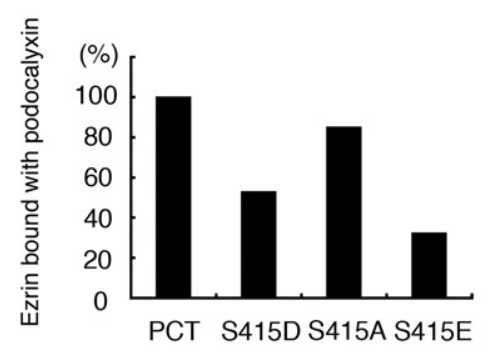

Figure 3. Interaction between PC and ezrin is inhibited in PAN-nephrotic glomeruli and in a mutant mimicking phosphorylation of the PKC phosphorylation site (Ser415) of PC. A: GST-N'-Ezrin binds His-PCT directly when the latter is either sham-treated (lane 3) or treated with PKA (lane 9), but binding is markedly reduced when His-PCT is phosphorylated with PKC (lane 6). In vitro binding assays were performed using sham-treated or in vitro phosphorylated 6-His-tagged PC tail (6-His-PCT) with GST-N'-Ezrin immobilized on glutathione S-sepharose beads. Bound proteins were analyzed by immunoblotting with His antibody (IB). Top panel shows an immunoblot, and bottom panel shows Ponceau S staining for the same blot. B: Interaction between endogenous PC and ezrin is decreased in PAN-nephrotic glomeruli. Pull-down assays were performed on glomerular lysates (normal versus 10 days PAN) with GST or GST-N'-Ezrin immobilized on glutathione S-sepharose beads. Bound proteins were analyzed by immunoblotting with PC antibody (0601). GST-N'-Ezrin bound strongly to PC from normal glomerular lysates (lane 3) but weakly to PC from PAN-nephrotic glomeruli (lane 6). Top panel shows an Immunoblot (WB), and the bottom panel shows Ponceau S staining for the same blot. C: In vitro binding assay between 6-His-tagged PC proteins and GST-N'ezrin. 6-His-PCT (aa 411 to 485); $\Delta$ N12, a juxtamembrane $\mathrm{N}$ terminal truncation mutant ( $\Delta$ 411-422); S415E, a phosphomimetic PC mutant; and S415A, a phospho-deficient PC mutant, were incubated with GST-N'-ezrin, and bound proteins were detected by immunoblotting with anti-PC 0601. PCT, PC S415E and PC S415A, but not PCT- $\Delta$ N12 bind to N'-ezrin. D: Densitometric analysis of data in C showing that binding of PC S415A or PC S415E to ezrin is weaker than that of PCT. E: In vitro binding assay between GST-PC tail mutants and in vitro-translated, ${ }^{35}$ S-labeled N-terminal ezrin. GST-PC and PC S415D and S415E (phosphomimetic mutants of PC) and S415A (a phosphodeficient mutant), were incubated with ${ }^{35}$ S-labeled, N-terminal ezrin in binding buffer and processed for autoradiography. F: Densitometric analysis of data in $\mathbf{E}$ showing that binding of the S415D and S415E phosphomimetic mutants is weaker than that of PCT or the phospho-deficient S415A mutant. 
harose beads and in vitro phosphorylated 6-Histidine (6His)-tagged PC tail (6-His-PCT) followed by immunoblotting to detect PC bound to ezrin. As shown previously, control (sham-treated) 6-His-PCT bound to GST-N'-Ezrin; however, binding was virtually abolished when PCT was phosphorylated with PKC. The binding remained unaltered when PCT was incubated with PKA (Figure 3A).

To test whether the binding of hyperphosphorylated podocalyxin to ezrin is also decreased in PAN nephrotic glomeruli we performed a GST pull-down assay from glomerular lysates with GST-N'-Ezrin and immunoblotted for podocalyxin. We found that binding was strikingly decreased in glomerular lysates from 10-day PAN rats versus controls (Figure 3B), indicating that hyperphosphorylated podocalyxin from PAN nephrotic glomeruli binds poorly to ezrin compared with podocalyxin from normal glomeruli.

Next we tested 6-His-PCT, 6-His-PCT $\Delta$ N12, 6-His-PC S415E (a phosphomimetic mutant of PC), and 6-His-PC S415A (a mutant incapable of being phosphorylated ${ }^{23}$ ) for their ability to bind to GST-N'-ezrin. As shown in Figure 3 C and D, PCT, PCT S415E, and PCT S415A, but not PCT $\triangle N 12$, bound to GST-N'ezrin. Binding of both PCT S415E and PCT S415A was weaker than that of PCT; S415E showed a marked reduction and S415A had an intermediate level of binding. Similar results were obtained by a complementary binding assay using GST-PC fusion proteins and in vitro-translated ezrin (Figure 3, E and F). These results indicate that Ser415 is a key determinant of $\mathrm{PC}$-ezrin interaction, and any perturbation of the site by mutagenesis or by phosphorylation reduces direct interaction between PC and ezrin.

\section{$P C$ Co-Localizes with Actin in MDCK-PC and MDCK-S415A Cells, but Not in MDCK-S415E Cells}

We previously showed that PC is attached to actin via ezrin in normal podocytes, whereas this connection is partially uncoupled in podocytes from PAN-nephrotic rats. ${ }^{10}$ We used immunofluorescence to assess whether PC phospho-mutants affect attachment to actin. For this purpose, we generated MDCK cell lines stably expressing wild-type PC (MDCK-PC) and the phosphomimetic MDCKS415E or phospho-deficient MDCK-S415A mutants. PC was seen exclusively along the apical membrane in MDCKPC, MDCK-S415E and MDCK-S415A cells, but not in control, MDCK-mock cells that do not express PC (Figures 4 and 5). Colocalization of PC with actin was extensive in MDCK-PC cells (Figures 4D and 5D), decreased markedly in MDCK-S415E cells (Figures 4G and 5G) and intermediate in phospho-deficient MDCK-S415A cells (Figures $4 \mathrm{~J}$ and $5 \mathrm{~J}$ ), indicating that phosphorylation or mutagenesis of Ser415 leads to defective localization of PC and PC-bound complexes to the apical actin bed.

\section{PC, Ezrin, and NHERF1 Dissociate from Actin Cytoskeleton in MDCK-S415E Cells but Not in MDCK-PC and MDCK-S415A Cells}

We have previously shown that when PC is expressed in MDCK cells it increases the interaction between
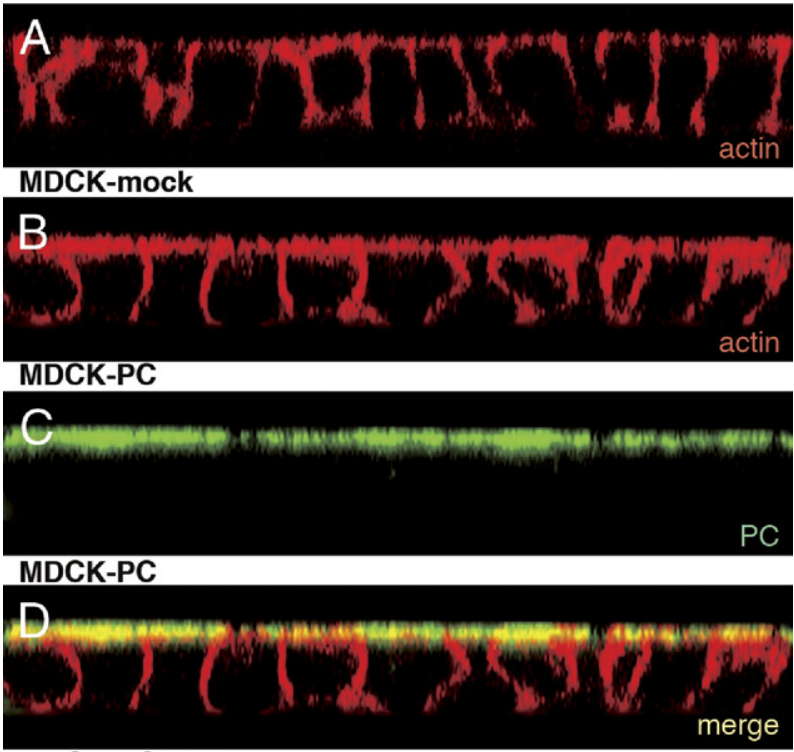

MDCK-PC

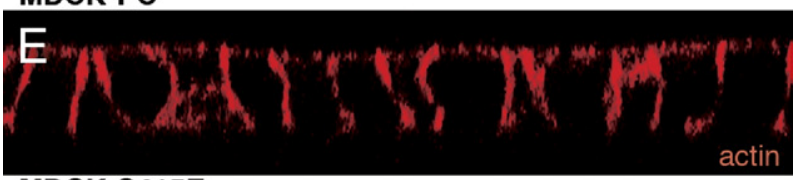

MDCK-S415E
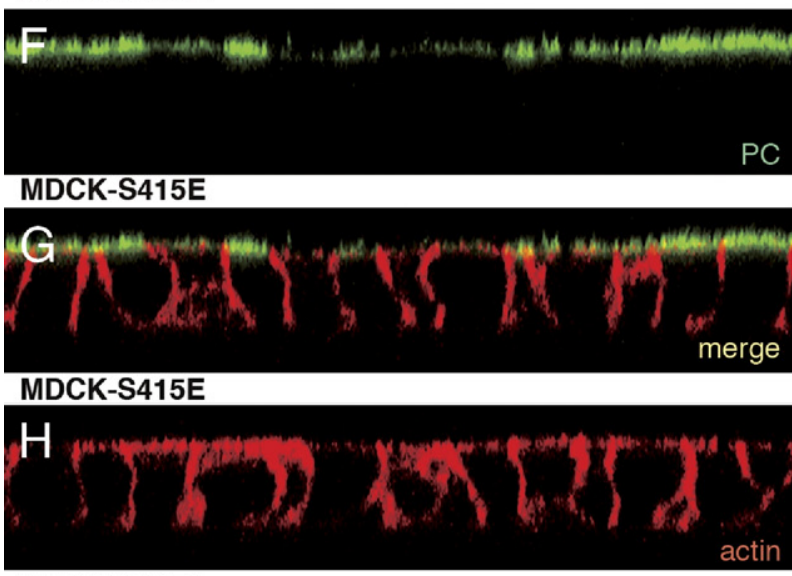

MDCK-S415A

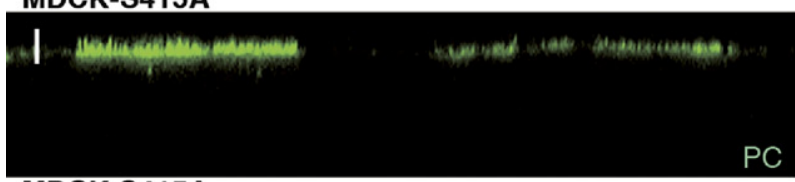

MDCK-S415A

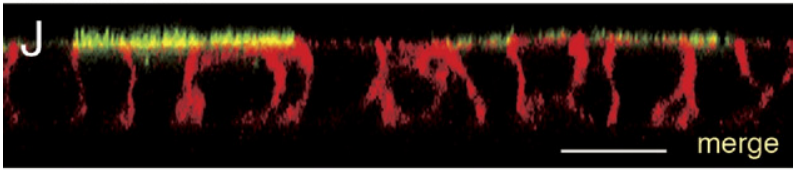

\section{MDCK-S415A}

Figure 4. Confocal microscopy showing that the colocalization of PC with actin is reduced in MDCK-S415E cells expressing phosphomimetic PC mutants (vertical or $\mathrm{X}-\mathrm{Z}$ sections). Staining for actin (red) and $\mathrm{PC}$ (green) in MDCK cell lines stably expressing wild-type PC (MDCK-PC) or PCT mutants. A: Distribution of actin in MDCK-mock cells that do not express podoclyxin. B-D: In MDCK-PC cells PC and actin overlap at the apical cell surface (yellow in D). E-G: In phosphomimetic MDCK-S415E cells co-localization of PC and actin is greatly decreased (yellow in G). H-J: In phospho-deficient MDCK-S415A cells, some colocalization is seen (yellow in $\mathbf{J}$ ). Cells were grown on filters, stained for actin with Alexa 594-phalloidin (1:200) and with anti-PC 5A IgG (1:50), and analyzed by confocal microscopy. Scale bar $=15 \mu \mathrm{m}$. 

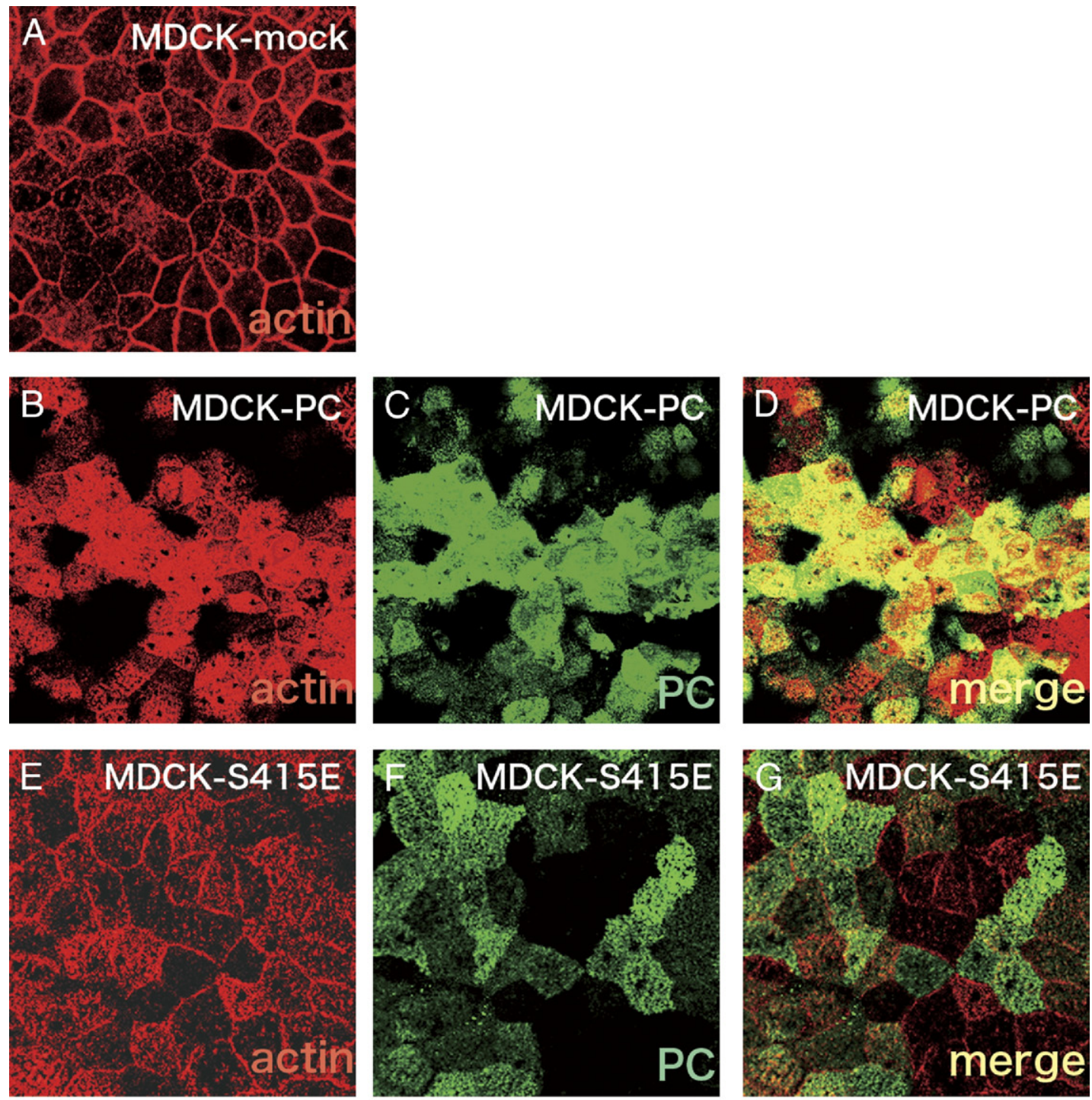

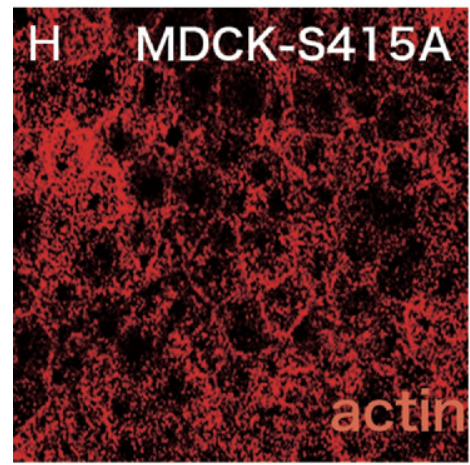

actin

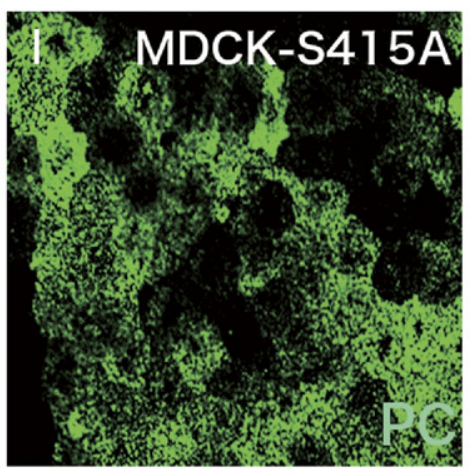

PC

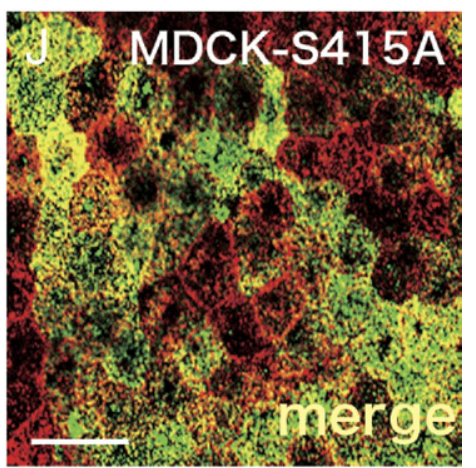

merge

Figure 5. Horizontal sections at the apical level showing staining for actin and PC in MDCK cells. MDCK cells transfected with the empty vector (MDCK-mock; A) were used as controls. In MDCK-PC (B-D) and MDCK-S415A (H-J) cells, PC and actin overlap (yellow in D and $\mathbf{J}$, respectively), whereas co-localization between PC and actin is decreased in MDCK-S415E cells $(\mathbf{E}-\mathbf{G})$. Cells were grown and processed as in Figure 4 . Scale bar $=15 \mu \mathrm{m}$.

ezrin and actin. ${ }^{9}$ Next we used differential detergent extraction $^{9,10}$ (which preserves cytoskeletal integrity and the interactions of noncytoskeletal proteins with $\operatorname{actin}^{24,25}$ ) to assess the connection between PC/ezrin and actin in MDCK cells expressing PC phospho-mutants versus controls. Cells were sequentially extracted in Triton X-100 and RIPA buffer and separated into Triton X-100-soluble, RIPA-soluble, and RIPA-insolu- 
A

$\frac{\text { Mock }}{\text { TS RS RI TS RS RI TS RS RI }} \frac{\text { PC }}{\text { TS RS RI }}$

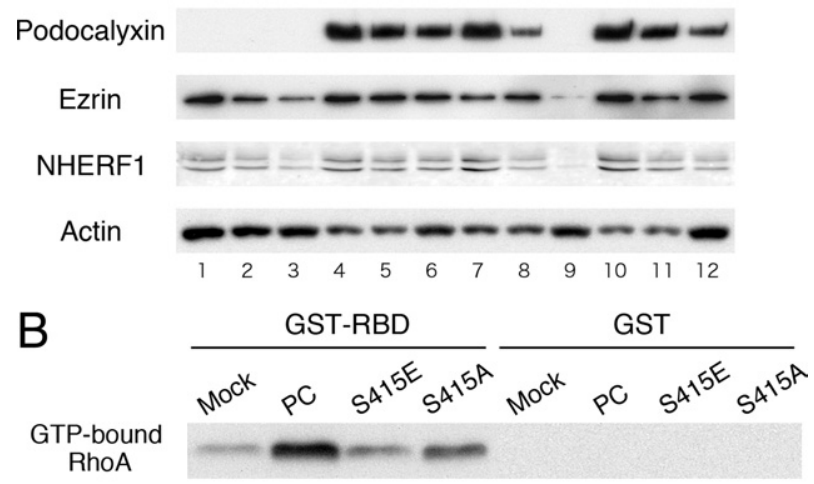

Total RhoA

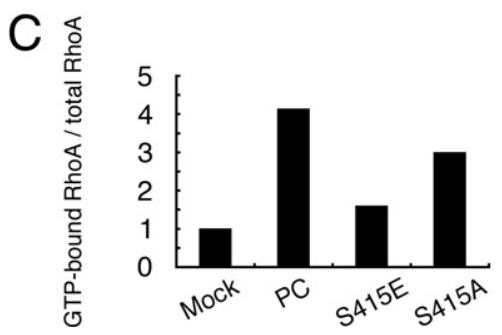

Figure 6. Dissociation of PC, ezrin, and NHERF1 from the actin cytoskeleton in MDCK-S415E cells expressing a phosphomimetic PC mutant. A: In wildtype MDCK-PC cells, PC is distributed in the Triton X-100 soluble (TS), RIPA soluble (RS), and RIPA insoluble (RI) fractions (lanes 4, 5, and 6, respectively) as shown previously. ${ }^{9}$ By contrast, in the phosphomimetic MDCKS415E cells, PC is mainly detected in the TS fraction (lane 7) and is greatly reduced in the RS fraction (lane 9). The amount of PC found in the RI fraction is also reduced in the phospho-deficient MDCK-S $415 \mathrm{~A}$ (lanes 10-12). Ezrin and NHERF1 are also distributed in all three fractions in MDCK-PC cells (lanes 4-6), but the amount found in the RI fraction is decreased in the phosphomimetic MDCK-S415E cells (lane 9) and MDCK-mock (lane 3) compared with the MDCK-PC (lane 6) and MDCK-S415A cells (lane 12). MDCK cells were sequentially extracted in Triton X-100 and RIPA buffer as described in Materials and Methods, and equal volumes of each fraction were immunoblotted for PC, ezrin. and actin. B: Amount of GTP-bound active RhoA (upper panel) is higher in MDCK-PC and MDCK-S415A than in MDCK-mock and MDCK-S415E cells. The amount of total RhoA (lower panel) is similar in all cell lines. GST-RhoA binding domain (GST-RBD) was incubated with $700 \mu \mathrm{L}$ cell lysate, and total RhoA and GTP-bound RhoA were detected with anti-RhoA IgG (1:200). As a negative control, lysates were also incubated with GST alone (GST). C: Densitometric analysis reveals that RhoA activity in MDCK-PC and phospho-deficient MDCK-S415A cells is approximately fourfold and threefold higher, respectively, than in MDCK-mock cells whereas RhoA activity in the phosphomimetic MDCK-S415E cells is greatly reduced. The relative RhoA activity was calculated from the ratios of GTP-bound RhoA/total RhoA and normalized to the ratio obtained for MDCK-mock cells.

ble fractions (Figure 6A). After extraction of MDCK-PC cells, $\mathrm{PC}$ was found in all three fractions, as reported previously. ${ }^{9}$ By contrast, in the phosphomimetic S415E cells there was a significant shift from the detergentinsoluble to the detergent-soluble fractions, and the amount of PC found in the RIPA-insoluble (RI) fraction was greatly decreased. The amounts of ezrin and NHERF1 found in the RI (actin-bound) fraction of MDCK-S415E cells were smaller than in MDCK-PC, MDCK-S415A, and MDCKmock cells. Taken together, these observations indicate that phosphorylation of PC leads to dissociation of PC/ezrin/ NHERF1 from actin.

\section{Activation of RhoA and Ezrin Is Reduced in Phosphomimetic MDCK-S415E Cells}

We have previously shown that PC activates RhoA and ezrin. ${ }^{9}$ To find out whether the phosphorylation status of $\mathrm{PC}$ affects RhoA activation, we performed in vitro binding assays for active RhoA. ${ }^{22}$ The ratio of GTP-bound, active RhoA to total RhoA was much lower in the phosphomimetic MDCK-S415E cells compared with MDCK-PC cells, and the phospho-deficient MDCK-S415A cells showed intermediate levels of activation (Figure 6 B and C). All MDCK cell lines showed similar levels of total RhoA. These results indicate that mimicking phosphorylation of PC at Ser415 suppresses the ability of podocalyxin to activate RhoA.

RhoA has been shown to activate ezrin by phosphorylation of Thr567, ${ }^{9,11,12}$ and activated ezrin anchors PC to actin in podocytes. To assess whether phosphorylated PC affects the activation of ezrin via RhoA, we used an antibody specific for activated ezrin. All MDCK cell lines showed similar levels of total ezrin, but the ratio of activated phospho-ezrin to total ezrin was lower in the phosphomimetic MDCK-S415E and MDCK-mock cells than in MDCK-PC and the phospho-deficient MDCK-S415A cells (Figure 7). Thus phosphorylation of $\mathrm{PC}$ leads to reduced activation of both ezrin and RhoA and leads to dissociation of PC from the actin cytoskeleton.

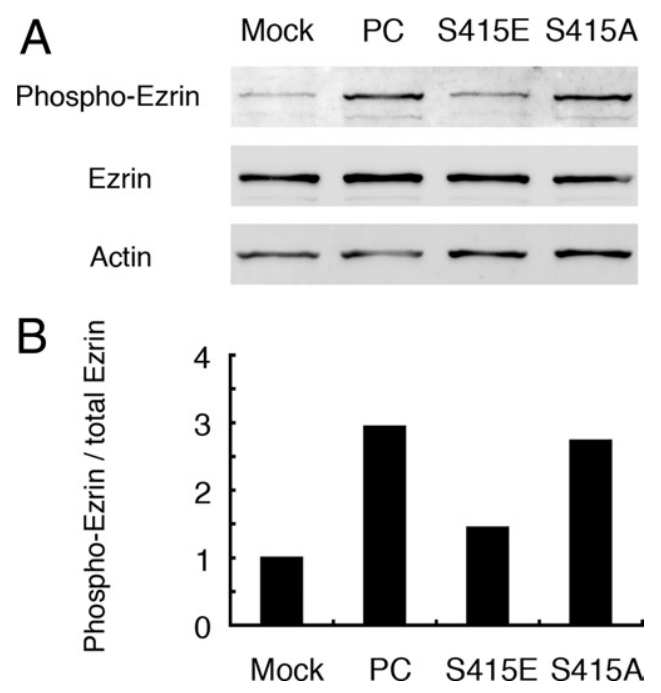

Figure 7. Ezrin is activated in MDCK-PC and phospho-negative MDCKS415A cells, but not in MDCK-S415E cells. A: Western blot analysis of phosphorylated ezrin (Phospho-Ezrin) and total ezrin (Ezrin) in MDCK cells. All MDCK cells show similar levels of total ezrin, but phospho-ezrin is higher in MDCK-PC and MDCK-S415A cells than in MDCK-mock and MDCK-S415E cells. MDCK cells were directly solubilized in $1 \times$ sample buffer and immunoblotted with anti-ezrin (1:20,000) or anti-phosphothr567-specific ezrin (1:1000) IgG. Actin was used as a control. B: Densitometric analysis indicating that activated ezrin is greatly increased in MDCK-PC and phosphodeficient MDCK-S415A cells, compared with MDCK-mock cells and phosphomimetic MDCK-S415E cells. Activated ezrin was calculated from the ratios of phospho-ezrin/total ezrin and normalized to the ratio obtained for MDCK-mock cells. 


\section{Discussion}

Many membrane proteins are firmly anchored to the actin cytoskeleton, which provides structural support to the cell membrane, determines cell shape, and creates membrane domains and microdomains of distinctive composition. Podocalyxin is a key apical membrane protein of podocytes that is anchored to actin and is essential for maintaining the characteristic foot process and filtration slit organization. In glomerular diseases associated with proteinuria and foot process effacement, there is typically extensive reorganization of the actin cytoskeleton of podocytes $^{2}$ and reduced expression ${ }^{26,27}$ or sialylation ${ }^{24,27,28}$ of podocalyxin, but the molecular events involved are still not fully understood. We have previously shown that PC is connected to actin through NHERF and ezrin, forming $\mathrm{PC} / \mathrm{NHERF} /$ ezrin/actin complexes that maintain normal foot process architecture, and that these complexes are disrupted in experimental models of nephrosis. ${ }^{8-10}$ In this work we show that phosphorylation of PC is increased in both PAN- and PS-treated glomeruli, and we demonstrate that phosphorylation of PC at Ser415 prevents direct binding of PC to ezrin, affects RhoA activity, and interferes with anchoring of PC to the actin cytoskeleton.

Our findings support the following model by which phosphorylated PC causes the dissociation between PC/ ezrin/NHERF and the actin cytoskeleton and leads to disruption of foot process architecture in nephrosis (Figure 8): Phosphorylation of PC at Ser415 decreases ezrin binding to PC and releases Rho-GDI from ezrin, which

\section{Phosphorylation of PC at Ser 415 by PKC in nephrosis}

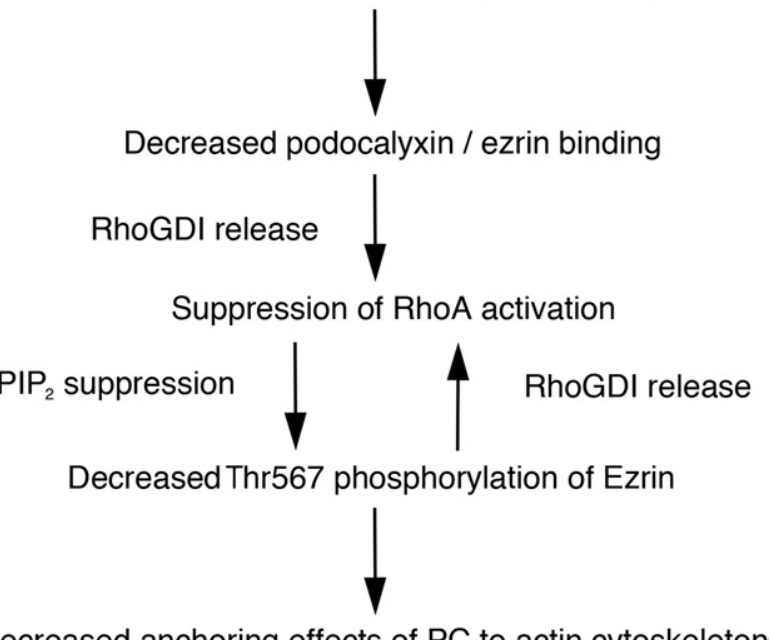

Decreased anchoring effects of PC to actin cytoskeleton

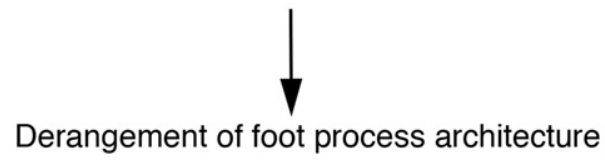

Figure 8. Proposed model for the phosphorylated PC-induced dissociation of PC from the actin cytoskeleton in nephrosis. Phosphorylation of Ser415 located in the juxtamembrane region of PC by PKC decreases direct binding to ezrin and releases RhoGDI from ezrin which suppresses RhoA activation. Suppressed RhoA prevents ezrin phosphorylation via $\mathrm{PIP}_{2}$ suppression. Ezrin changes its conformation, resulting in $\mathrm{NH}_{2}$ terminal-to-COOH terminal interaction, which masks the $\mathrm{COOH}$ terminal actin binding site. As a result, $\mathrm{PC} /$ ezrin complexes dissociate from the actin cytoskeleton. binds and inactivates RhoA. Inactive, GDP-bound RhoA prevents ezrin activation via phosphatidylinositol 4,5-bisphosphate $\left(\mathrm{PIP}_{2}\right),{ }^{11}$ and inactive (nonphosphorylated) ezrin dissociates from the actin cytoskeleton resulting in foot process effacement.

Although podocalyxin was originally discovered based on its properties as the major sialoprotein on podocytes, ${ }^{29}$ recently it has become evident that $\mathrm{PC}$ is widely expressed on blood cells, neurons, stem cells, ${ }^{30}$ and tumor cells ${ }^{30,31}$ and plays an important role in such diverse normal and pathological processes as neuronal development ${ }^{32}$ and cancer metastasis. ${ }^{33}$ Moreover, podocalyxin has two closely related family members: CD34 ${ }^{30,34}$ which is also a direct substrate of PKC in vitro and in vivo, and endoglycan. ${ }^{35}$ In addition, two other unrelated membrane proteins, CD44 and ICAM-3, which are also ezrin-binding partners, were shown to be phosphorylated by PKC at similar serine residues in their juxtamembrane regions. ${ }^{36,37}$ Phosphorylation of the juxtamembrane serine residue of CD44 was shown to modulate direct interaction with ezrin and to be critical for CD44-dependent directional cell motility. ${ }^{37}$ All these proteins have in common not only that they have a juxtamembrane PKC phosphorylation site, but also they are all heavily sialylated, O-linked glycoproteins. Thus phosphorylation of the juxtamembrane region by PKC may represent a common paradigm by which sialomucinated receptors regulate dynamic changes in membrane/cytoskeletal interactions and influence cell behavior.

We previously demonstrated that expression of PC in MDCK cells activates $\mathrm{RhoA}^{9}{ }^{9}$ and it has been reported that Rho activity is reduced in podocytes treated with PAN. ${ }^{38}$ Our current findings show for the first time that the phosphorylation status of Ser415 in PC affects RhoA activity. We also show that Thr567 phosphorylation of ezrin (and thereby its activation) is reduced in cells expressing the phosphomimetic PC mutant in MDCK cells, and that this effect coincides with inactivation of RhoA. These observations are consistent with the fact that activation of RhoA results in ezrin activation by stimulating phosphorylation of Thr567 of ezrin via $\mathrm{PIP}_{2}$, which disrupts the $\mathrm{NH}_{2}$ terminal-to- $\mathrm{COOH}$ terminal interaction and exposes the $\mathrm{COOH}$ terminal actinbinding site. ${ }^{11,39}$ Moreover, activated ezrin binds and sequesters RhoGDI, ${ }^{14-17}$ a negative regulator of Rho GTPases, thereby maintaining ezrin activation. ${ }^{18}$ Therefore, RhoA and ezrin constitute a positive feedback loop.

Our current results indicate that phosphoregulation of the direct interaction between PC and ezrin is required for activation of RhoA, because phospho-mimetic mutants of $\mathrm{PC}$ that prevent binding of $\mathrm{PC}$ to ezrin also prevent RhoA activation in MDCK cells. Of note, both phosphomimetic $(\mathrm{S} \rightarrow \mathrm{D} / \mathrm{E})$ and phospho-deficient $(\mathrm{S} \rightarrow \mathrm{A})$ substitutions at Ser415 shared similar changes in ezrin-binding (in vitro) and functional readouts (actin colocalization, RhoA and ezrin activity in MDCK cells) compared with wild-type PC. Although the phosphomimetic S415E mutant showed the greatest reduction in all our assays, the phospho-deficient S415A mutant consistently displayed an intermediate effect/phenotype. This indicates that Ser415 is critical to the function and possibly the structure of the core ezrin-binding motif, ${ }^{411} \mathrm{HQRIS}{ }^{415}$, on the PC tail, such that 
its disruption by either mutagenesis or by direct phosphorylation result in a varying degree of loss in ezrin binding. Our observation that the $\mathrm{S} \rightarrow$ A substitution had a similar effect as $S \rightarrow D$ is not unusual because it has been observed previously ${ }^{40-42}$ when the candidate serine is a key structural and functional component of the interacting surface between two binding partners.

We have previously shown that, in addition to RhoA activation, PC expression in MDCK cells modifies the distribution of junctional proteins and decreases transepithelial resistance. ${ }^{7,9}$ Because RhoA and Rac1 are known to be involved in regulation of tight junction structure and function, ${ }^{43}$ it is possible that phosphorylation of PC directly affects the permeability of the slit diaphragm (the junctional complex between foot processes ${ }^{44,45}$ ) in the nephrotic syndrome via RhoA inactivation. Further studies are required to determine whether this is the case.

In conclusion, we show here that hyperphosphorylation of Ser415 of PC by PKC disrupts the link between $\mathrm{PC} / \mathrm{ezrin} / \mathrm{NHERF}$ and the actin cytoskeleton via inactivation of RhoA and ezrin. The mechanistic insights gained elucidate how hyperphosphorylation of PC may contribute to derangement of the foot process architecture in pathological conditions such as minimal change disease and focal glomerulosclerosis.

\section{References}

1. Mundel P, Shankland SJ: Podocyte biology and response to injury. J Am Soc Nephrol 2002, 13:3005-3015

2. Oh J, Reiser J, Mundel P: Dynamic (re)organization of the podocyte actin cytoskeleton in the nephrotic syndrome. Pediatr Nephrol 2004 19:130-137

3. Pavenstadt $\mathrm{H}$, Kriz W, Kretzler M: Cell biology of the glomerular podocyte. Physiol Rev 2003, 83:253-307

4. Lachapelle M, Bendayan M: Contractile proteins in podocytes: immunocytochemical localization of actin and alpha-actinin in normal and nephrotic rat kidneys. Virchows Arch B Cell Pathol Incl Mol Pathol 1991, 60:105-111

5. Whiteside $\mathrm{Cl}$, Cameron R, Munk S, Levy J: Podocytic cytoskeletal disaggregation and basement-membrane detachment in puromycin aminonucleoside nephrosis. Am J Pathol 1993, 142:1641-1653

6. Kubosawa $\mathrm{H}$, Kondo $\mathrm{Y}$ : Modulation of cytoskeletal organization of podocytes during the course of aminonucleoside nephrosis in rats. Pathol Int 1994, 44:578-586

7. Takeda T, Go WY, Orlando RA, Farquhar MG: Expression of podocalyxin inhibits cell-cell adhesion and modifies junctional properties in Madin-Darby canine kidney cells. Mol Biol Cell 2000, 11:3219-3232

8. Orlando RA, Takeda T, Zak B, Schmieder S, Benoit VM, McQuistan T, Furthmayr H, Farquhar MG: The glomerular epithelial cell anti-adhesin podocalyxin associates with the actin cytoskeleton through interactions with ezrin. J Am Soc Nephrol 2001, 12:1589-1598

9. Schmieder S, Nagai M, Orlando RA, Takeda T, Farquhar MG: Podocalyxin activates RhoA and induces actin reorganization through NHERF1 and Ezrin in MDCK cells. J Am Soc Nephrol 2004, 15:2289-2298

10. Takeda T, McQuistan T, Orlando RA, Farquhar MG: Loss of glomerular foot processes is associated with uncoupling of podocalyxin from the actin cytoskeleton. J Clin Invest 2001, 108:289-301

11. Matsui T, Yonemura S, Tsukita S: Activation of ERM proteins in vivo by Rho involves phosphatidyl-inositol 4-phosphate 5-kinase and not ROCK kinases. Curr Biol 1999, 9:1259-1262

12. Bretscher A, Edwards K, Fehon RG: ERM proteins and merlin: integrators at the cell cortex. Nat Rev Mol Cell Biol 2002, 3:586-599

13. Fehon RG, McClatchey Al, Bretscher A: Organizing the cell cortex: the role of ERM proteins. Nat Rev Mol Cell Biol 2010, 11:276-287
14. Hirao M, Sato N, Kondo T, Yonemura S, Monden M, Sasaki T, Takai Y, Tsukita S: Regulation mechanism of ERM (ezrin/radixin/moesin) protein/plasma membrane association: possible involvement of phosphatidylinositol turnover and Rho-dependent signaling pathway. J Cell Biol 1996, 135:37-51

15. Takahashi K, Sasaki T, Mammoto A, Takaishi K, Kameyama T, Tsukita S, Takai Y: Direct interaction of the Rho GDP dissociation inhibitor with ezrin/radixin/moesin initiates the activation of the Rho small $G$ protein. J Biol Chem 1997, 272:23371-23375

16. Maeda M, Matsui T, Imamura M, Tsukita S: Expression level, subcelIular distribution and rho-GDI binding affinity of merlin in comparison with Ezrin/Radixin/Moesin proteins. Oncogene 1999, 18:4788-4797

17. Hamada K, Seto A, Shimizu T, Matsui T, Takai Y, Tsukita S, Hakoshima T: Crystallization and preliminary crystallographic studies of RhoGDI in complex with the radixin FERM domain. Acta Crystallogr D Biol Crystallogr 2001, 57:889-890

18. Bretscher A, Chambers D, Nguyen R, Reczek D: ERM-Merlin and EBP50 protein families in plasma membrane organization and function. Annu Rev Cell Dev Biol 2000, 16:113-143

19. Kerjaschki D: Polycation-induced dislocation of slit diaphragms and formation of cell junctions in rat kidney glomeruli: the effects of low temperature, divalent cations, colchicine, and cytochalasin B. Lab Invest 1978, 39:430-440

20. Kanwar YS, Farquhar MG: Detachment of endothelium and epithelium from the glomerular basement membrane produced by kidney perfusion with neuraminidase. Lab Invest 1980, 42:375-384

21. Lehtonen S, Lehtonen E, Kudlicka K, Holthofer H, Farquhar MG: Nephrin forms a complex with adherens junction proteins and CASK in podocytes and in Madin-Darby canine kidney cells expressing nephrin. Am J Pathol 2004, 165:923-936

22. Ren XD, Kiosses WB, Schwartz MA: Regulation of the small GTPbinding protein Rho by cell adhesion and the cytoskeleton. EMBO 1999, 18:578-585

23. Pitula JS, Deck KM, Clarke SL, Anderson SA, Vasanthakumar A, Eisenstein RS: Selective inhibition of the citrate-to-isocitrate reaction of cytosolic aconitase by phosphomimetic mutation of serine-711. Proc Natl Acad Sci USA 2004, 101:10907-10912

24. Lenk R, Ransom L, Kaufmann Y, Penman S: A cytoskeletal structure with associated polyribosomes obtained from HeLa cells. Cell 1977, 10:67-78

25. Fey EG, Capco DG, Krochmalnic G, Penman S: Epithelial structure revealed by chemical dissection and unembedded electron microscopy. J Cell Biol 1984, 99:203s-208s

26. Kovoura E, Gakiopoulou H, Paraskevakou H, Marinaki S, Agrogiannis G, Stofas A, Boletis I, Patsouris E, Lazaris AC: Immunohistochemical evaluation of podocalyxin expression in glomerulopathies associated with nephrotic syndrome. Hum Pathol 2011, 42:227-235

27. Kerjaschki D, Vernillo AT, Farquhar MG: Reduced sialylation of podocalyxin - the major sialoprotein of the rat kidney glomerulus-in aminonucleoside nephrosis. Am J Pathol 1985, 118:343-349

28. Galeano B, Klootwijk R, Manoli I, Sun M, Ciccone C, Darvish D, Starost MF, Zerfas PM, Hoffmann VJ, Hoogstraten-Miller S, Krasnewich DM, Gahl WA, Huizing M: Mutation in the key enzyme of sialic acid biosynthesis causes severe glomerular proteinuria and is rescued by N-acetylmannosamine. J Clin Invest 2007, 117:1585-1594

29. Kerjaschki D, Sharkey DJ, Farquhar MG: Identification and characterization of podocalyxin-the major sialoprotein of the renal glomerular epithelial cell. J Cell Biol 1984, 98:1591-1596

30. Nielsen JS, McNagny KM: Novel functions of the CD34 family. J Cell Sci 2008, 121:3683-3692

31. Nielsen JS, McNagny KM: The role of podocalyxin in health and disease. J Am Soc Nephrol 2009, 20:1669-1676

32. Vitureira N, Andres R, Perez-Martinez E, Martinez A, Bribian A, Blas J, Chelliah S, Lopez-Domenech G, De Castro F, Burgaya F, McNagny $\mathrm{K}$, Soriano E: Podocalyxin is a novel polysialylated neural adhesion protein with multiple roles in neural development and synapse formation. PLoS One 2010, 5:e12003

33. Hsu YH, Lin WL, Hou YT, Pu YS, Shun CT, Chen CL, Wu YY, Chen JY, Chen TH, Jou TS: Podocalyxin EBP50 ezrin molecular complex enhances the metastatic potential of renal cell carcinoma through recruiting Rac1 guanine nucleotide exchange factor ARHGEF7. Am J Pathol 2010, 176:3050-3061 
34. Fackler MJ, Civin Cl, Sutherland DR, Baker MA, May WS: Activated protein kinase $\mathrm{C}$ directly phosphorylates the CD34 antigen on hematopoietic cells. J Biol Chem 1990, 265:11056-11061

35. Sassetti C, Van Zante A, Rosen SD: Identification of endoglycan, a member of the CD34/podocalyxin family of sialomucins. J Biol Chem 2000, 275:9001-9010

36. Hayflick JS, Stine J, Fox R, Hoekstra D, Gallatin WM: Functional mapping of the cytoplasmic region of intercellular adhesion molecule-3 reveals important roles for serine residues. J Biol Chem 1997, 272:22207-22214

37. Legg JW, Lewis CA, Parsons M, Ng T, Isacke CM: A novel PKCregulated mechanism controls $\mathrm{CD} 44$ ezrin association and directional cell motility. Nat Cell Biol 2002, 4:399-407

38. Zheng CX, Chen ZH, Zeng CH, Qin WS, Li LS, Liu ZH: Triptolide protects podocytes from puromycin aminonucleoside induced injury in vivo and in vitro. Kidney Int 2008, 74:596-612

39. Zhu L, Zhou R, Mettler S, Wu T, Abbas A, Delaney J, Forte JG: High turnover of ezrin T567 phosphorylation: conformation, activity, and cellular function. Am J Physiol Cell Physiol 2007, 293:C874-884
40. Tang DC, Kang HM, Jin JP, Fraser ED, Walsh MP: Structure-function relations of smooth muscle calponin. The critical role of serine 175. J Biol Chem 1996, 271:8605-8611

41. Kacherovsky N, Tachibana C, Amos E, Fox D, 3rd, Young ET: Promoter binding by the Adr1 transcriptional activator may be regulated by phosphorylation in the DNA-binding region. PLoS One 2008, 3:e3213

42. Miyakawa Y, Drachman JG, Gallis B, Kaushansky A, Kaushansky K: A structure-function analysis of serine/threonine phosphorylation of the thrombopoietin receptor, c-Mpl. J Biol Chem 2000, 275:32214-32219

43. Jou TS, Schneeberger EE, Nelson WJ: Structural and functional regulation of tight junctions by RhoA and Rac1 small GTPases. J Cell Biol 1998, 142:101-115

44. Fukasawa H, Bornheimer S, Kudlicka K, Farquhar MG: Slit diaphragms contain tight junction proteins. J Am Soc Nephrol 2009 20:1491-1503

45. Huber TB, Benzing T: The slit diaphragm: a signaling platform to regulate podocyte function. Curr Opin Nephrol Hypertens 2005, 14 211-216 